\title{
Postpartum thyroid dysfunction in Mid Glamorgan
}

\author{
HEDY Y M FUNG, MINOSH KOLOGLU, KATE COLLISON, R JOHN, C J RICHARDS, \\ R HALL, A M MCGREGOR
}

\begin{abstract}
A high prevalence of postpartum thyroid dysfunction has been reported in several countries, but there have been no systematic studies of its prevalence in Britain. Among a group of 901 consecutive, unselected pregnant women thyroid autoantibodies were detected in $117(13 \%)$ at booking. The clinical course of postpartum thyroid dysfunction, factors associated with its development, and its likely prevalence were defined in 100 of these women with thyroid antibodies and 120 women with no such antibodies who were matched for age. None of the women had a history of autoimmune thyroid disease. Normal reference ranges for thyroid function during pregnancy and post partum were established in the 120 women negative for thyroid antibodies. On the basis of these observations postpartum thyroid dysfunction was observed in $49(22 \%)$ of the 220 women studied, and the prevalence in the total group of 901 women was estimated to be $16.7 \%$. Thyroid dysfunction, mainly occurring in the first six months post partum, was usually transient and included both destruction induced hyperthyroidism and hypothyroidism. The development of the syndrome was significantly related to smoking more than 20 cigarettes a day and the presence of thyroid microsomal autoantibodies at booking. Of the 16 women with a family history of thyroid disease in whom thyroid microsomal autoantibody activity was detectable at booking, 11 developed thyroid dysfunction. Age, parity, presence of goitre at presentation, duration of breast feeding, and the sex and birth weight of
\end{abstract}

Departments of Medicine and Medical Biochemistry, University of Wales College of Medicine, Cardiff

HEDY Y M FUNG, $M D$, research associate

MINOSH KOLOGLU, MD, research associate

KATE COLLISON, BSC, research associate

R JOHN, PHD, principal biochemist

R HALL, MD, FRCP, professor of medicine

A M MCGREGOR, MD, FRCP, senior lecturer

Department of Obstetrics and Gynaecology, Caerphilly District Miners' Hospital, Caerphilly

C J RICHARDS, FRCOG, consultant obstetrician

Correspondence to: Professor A M McGregor, Department of Medicine, King's College School of Medicine and Dentistry, London SE5 8RX. the infant were not associated with the development of postpartum thyroid dysfunction.

The mood changes experienced by women post partum may in part be associated with altered thyroid function during this time.

\section{Introduction}

Pregnancy seems to have a profound effect on thyroid function not only during gestation but also post partum..$^{1-3}$ This relation, particularly post partum, has long been documented,,$^{46}$ and evidence from several studies ${ }^{7.9}$ has led to the current recognition of postpartum thyroid dysfunction being autoimmune in origin. ${ }^{10} \mathrm{~A}$ high prevalence of postpartum thyroid dysfunction, mostly transient, has been reported from Japan, ${ }^{8}$ North America, ${ }^{11}$ and Scandinavia ${ }^{9}$ both in previously normal women and in those with known autoimmune thyroid disease. Jansson et al suggested that the presence of thyroid microsomal autoantibodies is of prognostic value in the development of postpartum thyroid dysfunction. ${ }^{9}$

The transient nature of this dysfunction, which usually has mild symptoms, means that many cases go unrecognised. Although sporadic cases of postpartum transient hypothyroidism are now being seen in Britain, ${ }^{12}$ a systematic study is required of the prevalence of this condition, especially in a population with no history of autoimmune thyroid disease. The clinical implications of postpartum thyroid dysfunction are still unclear, in particular the relation between thyroid dysfunction and well recognised postpartum changes in mood and behaviour and even the development of frank psychiatric illness. Defining the variables that identify women at risk would, besides better characterising the underlying pathogenetic processes, improve the management of women developing the disease. To characterise the condition, determine the factors associated with its development, and assess its prevalence we examined prospectively thyroid function, thyroid immune state, and relevant clinical information in women attending a maternity unit.

\section{Subjects and methods}

We obtained permission for the study from the ethical committees of the Mid and South Glamorgan Health Authorities and the subjects' informed consent. Altogether 901 consecutive women attending the antenatal booking 
clinic at Caerphilly District Miners' Hospital between April 1983 and January 1985 were screened for the presence of autoantibodies to thyroid microsomes and thyroglobulin by enzyme linked immunosorbent assay (ELISA). ${ }^{13}$ All women positive for thyroid autoantibody and an equal number of women matched for age who were negative for the antibody were then recruited into a prospective study.

The study group was seen at intervals of six weeks during pregnancy and for 12 months post partum. Any personal or family history of autoimmune thyroid disease was obtained, and clinical thyroid state was assessed at each visit by a thyroidologist, who did not know to which group the women had been assigned or their biochemical thyroid state. The size of the thyroid gland was recorded according to the following classification: $1=$ not palpable, $2=$ palpable and not enlarged, $3=$ palpable and enlarged, $4=$ visible, and $5=$ visible and large. When hyperthyroidism was suspected clinically during the period of follow up biochemical thyroid function tests were carried out as confirmation. Uptake of iodine (10 MBq iodine-123 orally) over four and 48 hours was measured in hyperthyroid women who were not breast feeding and consented to the procedure. Samples of maternal serum obtained at each visit and cord and maternal samples obtained at delivery were stored at $-20^{\circ} \mathrm{C}$ pending analysis of thyroid function and titres of thyroid autoantibodies at completion of follow up. All samples from each woman were assayed within the same assay to avoid interassay variation.

Gestation-The weeks of gestation were calculated from the last menstrual period. If this was not known, or if ultrasonography at booking showed a discrepancy of more than two weeks between the actual measurement of biparietal diameter and that calculated from the last menstrual period, the gestational age was calculated according to the fetal size measured from the scan.

Thyroid function-Circulating concentrations of free thyroxine, triiodothyronine, and thyroid stimulating hormone were measured with commercially available radioimmunoassay kits (Amerlex; Amersham International PLC). Evaluation of the assays throughout the study showed interassay variations of $6.6 \%$ for free thyroxine at a mean value of 15.1 $\mathrm{pmol} / 1,6 \cdot 6 \%$ for triiodothyronine at a mean value of $5 \cdot 5 \mathrm{pmol} / 1$, and $7 \cdot 7 \%$ for thyroid stimulating hormone at a mean value of $7.7 \mathrm{mU} / 1$.

Definition of postpartum thyroid dysfunction-A normal reference range for thyroid function during pregnancy and post partum was established from serial data obtained from the 120 women negative for thyroid autoantibodies in the study group (see below). Concentrations of free thyroid hormones and thyroid stimulating hormone were considered to be abnormal if they fell outside the mean $+2 \mathrm{SD}$ of the normal reference value measured at the same time. When two or more consecutive abnormal results were detected in a woman post partum she was defined as having postpartum thyroid dysfunction.

Thyroid autoantibodies were measured as absorbance (optical density) at $405 \mathrm{~nm}$ by ELISA. The normal ranges of absorbance for thyroid microsomal and thyroglobulin autoantibodies were established in 98 normal men and non-pregnant women with no family or personal history of thyroid disease and mean age 37 (SD 7). Antibody activity was considered to be detectable in the serum samples of the pregnant women if the titre observed was greater than the mean value $+2 \mathrm{SD}$ in the $\mathbf{9 8}$ normal subjects. The intraassay and interassay variations ranged from $4 \cdot 0 \%$ to $7 \cdot 9 \%$ and $9 \cdot 6 \%$ to $12 \cdot 8 \%$, respectively, for thyroid microsomal autoantibody, and from $5 \cdot 6 \%$ to $10 \cdot 8 \%$ and $12.9 \%$ to $14.4 \%$, respectively, for thyroglobulin autoantibody. The activity of antibodies to thyroid stimulating hormone receptor was examined with a human thyroid cell bioassay ${ }^{14} 15$ as previously described.$^{16}$

Statistical analysis-The data were analysed with the Minitab statistical computing system, version $8 \cdot 1$ (Pennsylvania State University, 1981). Statistical testing was either by paired two tailed Student's $t$ test or by contingency tables and the $\chi^{2}$ test.

\section{Results}

Assay of serum samples obtained at booking from the 901 women presenting to the antenatal clinic showed that 117 had detectable thyroid autoantibodies. Seventeen women who were positive for the antibodies were lost to follow up, and so the study group consisted of the remaining 100 women with the antibodies and 132 women who were negative for the antibodies. Analysis of changes in antibody activity during pregnancy and post partum in 84 women positive for microsomal autoantibodies showed a significant fall in activity during pregnancy (booking $v$ delivery $\mathrm{p}<0.001$; mean difference in optical density $=0.118,95 \%$ confidence interval 0.066 to $0 \cdot 169$ ) with a significant rebound in activity post partum (delivery $v 49-56$ weeks post partum $\mathrm{p}<0.001$; mean difference in optical density $=0.298$, $95 \%$ confidence interval 0.214 to 0.382 ) (fig 1 ). Twelve of the women who were negative for the antibodies conceived during the period of follow up and were therefore excluded from further analysis, and the data presented hereafter refer to the final study group of 220 women.

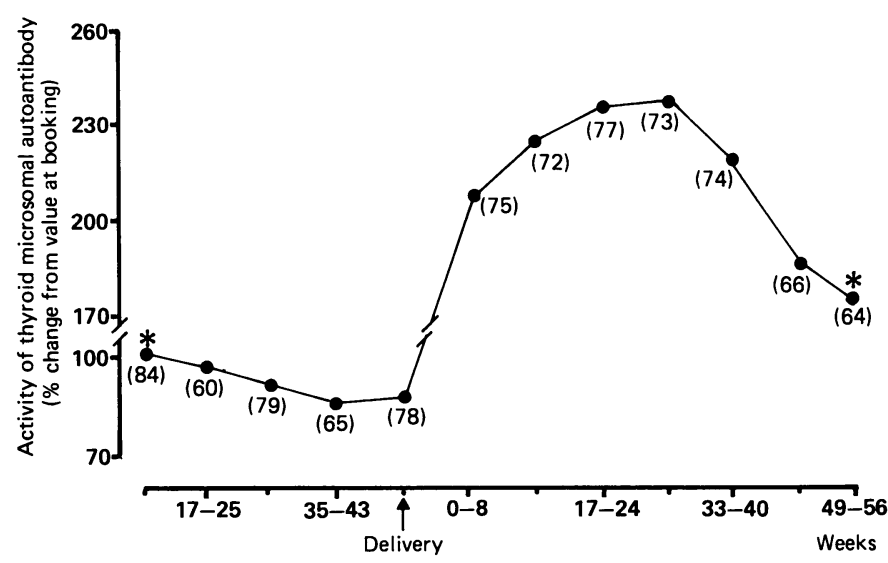

FIG 1-Changes in serum activity of thyroid microsomal autoantibody during pregnancy and 12 months post partum in 84 women who had detectable microsomal autoantibody. Numbers in parentheses indicate number of women assessed at each time point.

${ }^{\star} \mathrm{p}<0.001$ When compared with values at delivery.
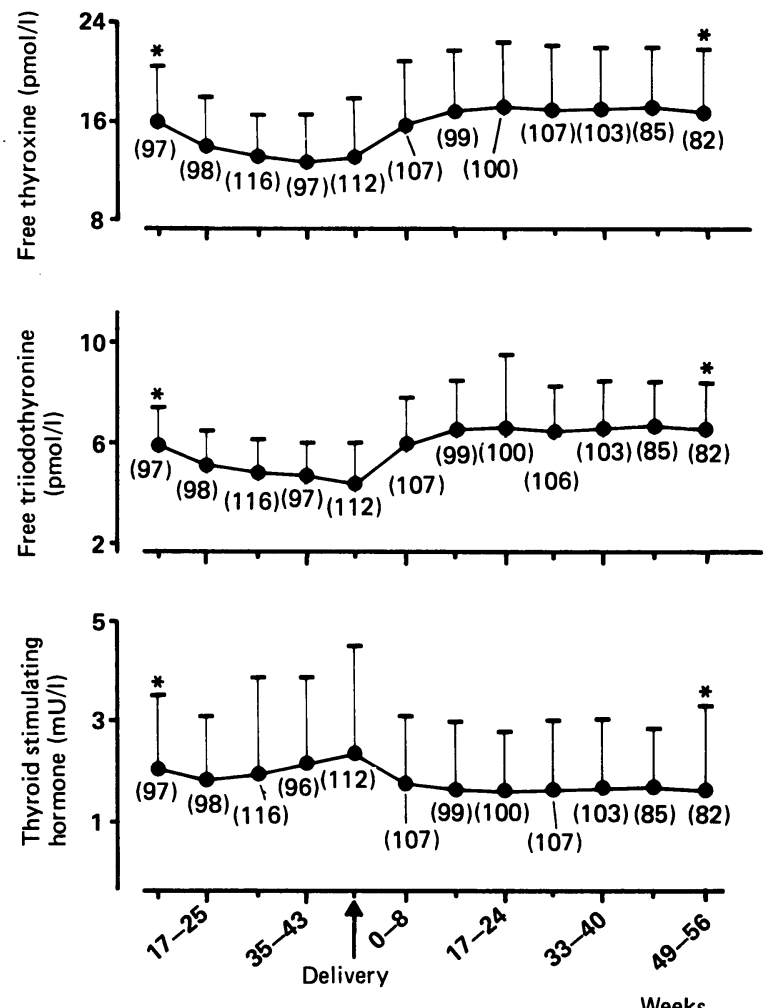

FIG 2-Mean (2 SD) changes in serum concentrations of thyroid stimulating hormone, free triiodothyronine, and free thyroxine during pregnancy and 12 months post partum in 120 women who were negative for microsomal autoantibodies. Figures in parentheses indicate number of women assessed at each time point.

${ }^{\star} \mathrm{p}<0.001$ When compared with values at delivery.

Thyroid function during pregnancy-Serial thyroid hormone concentrations in the 120 women with no thyroid autoantibodies showed a significant decrease in free thyroxine and triiodothyronine concentrations with increasing gestational age (booking $v$ delivery $\mathrm{p}<0.001$; mean difference in free thyroxine concentration $=2.94 \mathrm{pmol} / 1,95 \%$ confidence interval 2.39 to 3.49 $\mathrm{pmol} / \mathrm{l}$; mean difference in free triiodothyronine concentration $=1.60$ $\mathrm{pmol} / 1,95 \%$ confidence interval $1 \cdot 38$ to $1 \cdot 81 \mathrm{pmol} / 1$ ), which was accompanied by a significant increase in serum concentrations of thyroid stimulating hormone (booking $v$ delivery $\mathrm{p}<0.001$; mean difference in thyroid stimulating hormone concentration $=0.37 \mathrm{mU} / 1,95 \%$ confidence interval 0.64 to $1 \cdot 18 \mathrm{mU} / \mathrm{l}$ ) (fig 2). All three concentrations had returned to values found before pregnancy by six to nine weeks post partum; the values found 46-56 weeks post partum were taken as reflecting most closely concentrations of 
the three hormones observed before pregnancy (delivery $v 49-56$ weeks post partum $\mathrm{p}<0.001$; mean difference in free thyroxine concentration $=3.78$ $\mathrm{pmol} / \mathrm{l}, 95 \%$ confidence interval 3.08 to $4.48 \mathrm{pmol} / 1$; mean difference in free triiodothyronine concentration $=2.22 \mathrm{pmol} / 1,95 \%$ confidence interval 1.96 to $2.47 \mathrm{pmol} / \mathrm{l}$; mean difference in thyroid stimulating hormone concentration $=0.91 \mathrm{mU} / 1,95 \%$ confidence interval 0.64 to $1.18 \mathrm{mU} / \mathrm{l}$ ).

Postpartum thyroid dysfunction-Of the 220 women studied, $49(22.3 \%)$ developed postpartum thyroid dysfunction. Thirty seven of them had detectable thyroid autoantibodies at some time during the study, with 30 having the antibodies at presentation; only 12 women were negative for the antibodies throughout the study. Microsomal autoantibodies were detected in 32 of the 49 women who developed postpartum thyroid dysfunction. From this the prevalence of the condition in the unselected population of 901 women was estimated to be $17 \%$. The women with postpartum thyroid dysfunction could be categorised into four groups: group 1 had hyperthyroidism followed by hypothyroidism, group 2 hyperthyroidism alone, group 3 hypothyroidism alone, and group 4 hypothyroidism followed by hyperthyroidism (table I). The time of onset was 13.0 (SEM 2.3) weeks for

TABLE I-Numbers (percentages) of women developing postpartum thyroid dysfunction according to thyroid state and presence of autoantibodies

\begin{tabular}{|c|c|c|c|}
\hline Thyroid state & No of women & $\begin{array}{c}\text { Women with } \\
\text { thyroid } \\
\text { autoantibodies. }\end{array}$ & $\begin{array}{l}\text { Women with } \\
\text { thyroid } \\
\text { microsomal } \\
\text { autoantibodies }\end{array}$ \\
\hline $\begin{array}{l}\text { Hyperthyroidism then hypothyroidism } \\
\text { Hyperthyroidism alone } \\
\text { Hypothyroidism alone } \\
\text { Hypothyroidism then hyperthyroidism }\end{array}$ & $\begin{array}{rr}9 & (18) \\
21 & (43) \\
17 & (35) \\
2 & (4)\end{array}$ & $\begin{array}{r}8(16) \\
12(25) \\
15(31) \\
2(4)\end{array}$ & $\begin{array}{r}8(16) \\
9(18) \\
14(29) \\
1(2)\end{array}$ \\
\hline Total & $49(100)$ & $37(76)$ & $32(65)$ \\
\hline
\end{tabular}

^Antibodies to both thyroglobulin and the thyroid microsome.

hyperthyroidism and $20 \cdot 0(2 \cdot 5)$ weeks for hypothyroidism in group $1 ; 18.4$ $(2 \cdot 8)$ weeks for hyperthyroidism in group 2 ; and $21 \cdot 3(3 \cdot 2)$ weeks for hypothyroidism in group 3 . The episode of thyroid dysfunction resolved spontaneously in all but one woman in group 3 , who remained persistently hypothyroid 18 months post partum and required replacement of thyroxine. Suppressed uptakes of radioiodine by the thyroid $(<1 \%)$ at four and 48 hours were observed in all seven women examined at the time of their episode of documented biochemical hyperthyroidism. Clinical symptoms or signs did not provide a reliable guide to the development of thyroid dysfunction post partum.

Thyroid autoantibody state-There was a significant difference in the distribution of thyroid microsomal and thyroglobulin autoantibodies between the women who developed postpartum thyroid dysfunction and those who did not (table II). Despite the large difference in the prevalence of

TABLE II-Prevalence of thyroid autoantibodies in relation to development of postpartum thyroid dysfunction. Values are numbers (percentages) of women

\begin{tabular}{lcc}
\hline & $\begin{array}{c}\text { Women who } \\
\text { developed } \\
\text { postpartum } \\
\text { thyroid } \\
\text { dysfunction } \\
(\mathrm{n}=49)\end{array}$ & $\begin{array}{c}\text { Women who } \\
\text { did not develop } \\
\text { postpartum } \\
\text { thyroid } \\
\text { dysfunction } \\
(\mathrm{n}=171)\end{array}$ \\
\hline $\begin{array}{l}\text { Thyroid microsomal autoantibodies at booking } \\
\text { Thyroid microsomal autoantibodies during study }\end{array}$ & $27(55)$ & $27(16)^{\star} \dagger$ \\
$\begin{array}{l}\text { Thyroglobulin autoantibodies at any time } \\
\text { No antithyroid antibodies }\end{array}$ & $5(10)$ & $23(13)$ \\
$10(6)$ & $12(25)$ & $111(65)$
\end{tabular}

${ }^{\star} \chi^{2}=36.49, \mathrm{df}=3, \mathrm{p}<0.001$

+ Predictive value for development of postpartum thyroid dysfunction is $27 / 54=50 \%$.
$\chi$

microsomal autoantibodies at booking between these two groups of women this variable alone was of limited value in predicting the development of thyroid dysfunction. When the changes in activity of the antibodies were assessed in relation to the development of thyroid dysfunction, however, we found that, although autoantibody activity increased significantly post partum in all women who developed thyroid dysfunction and the mean time of onset of the particular presentation of dysfunction might differ, the peak activity of thyroid microsomal autoantibody tended to coincide with the mean time of onset of the dysfunction in groups 1-3 (fig 3). Assay of all 174 samples from the 21 women with transient hyperthyroidism in group 2 for activity of antibody to thyroid stimulating hormone receptor showed no evidence for the development of Graves' disease post partum.

Associated clinical features-There was no significant difference in age or the distribution of primigravidas and multigravidas between those who did and did not develop postpartum thyroid dysfunction (table III). A family history of thyroid disease was more common in the group who developed thyroid dysfunction, but the difference did not reach significance. When a

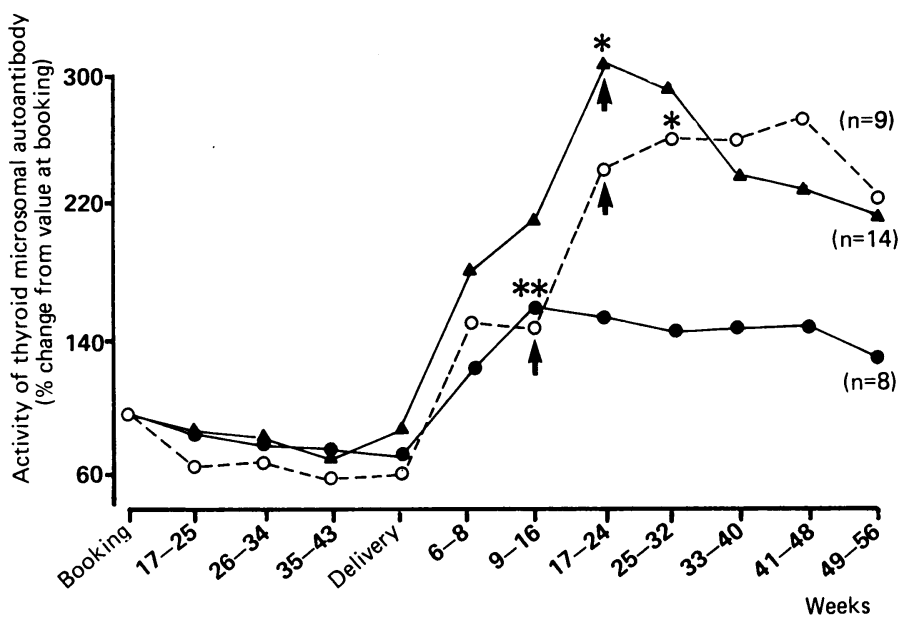

FIG 3-Relation between changes in activity of thyroid microsomal autoantibody and mean time of onset of postpartum thyroid dysfunction (arrows) in three groups of patients. $=$ Transient hyperthyroidism then transient hypothyroidism. $\bigcirc-. \bigcirc=$ Transient hyperthyroidism alone. $\boldsymbol{\Delta}-\boldsymbol{\Delta}=$ Transient hypothyroidism alone.

${ }^{\star} \mathrm{p}<0.05,{ }^{\star \star} \mathrm{p}<0.005$ Compared with values of antibody activity at booking (paired Student's $t$ test).

family history of thyroid disease and the presence of thyroid microsomal autoantibodies at booking were considered together the predictive value increa . ad from $50 \%$ (when the autoantibody state alone was considered) to $69 \%$. A family history of diabetes mellitus and of pernicious anaemia and the frequency and duration of breast feeding were no different in the two groups. No significant difference existed in the mean birth weights, the ratio of female to male neonates, or the size of the maternal thyroid gland at

TABLE III-Clinical features in relation to development of postpartum thyroid dysfunction

\begin{tabular}{|c|c|c|}
\hline & $\begin{array}{l}\text { Women who } \\
\text { developed } \\
\text { postpartum } \\
\text { thyroid } \\
\text { dysfunction } \\
(n=49)\end{array}$ & $\begin{array}{l}\text { Women who did } \\
\text { not develop } \\
\text { postpartum } \\
\text { thyroid } \\
\text { dysfunction } \\
(\mathrm{n}=17 \mathrm{l})\end{array}$ \\
\hline Mean (SD) maternal age (years) & $24 \cdot 8(4 \cdot 9)$ & $25 \cdot 5(4 \cdot 9)$ \\
\hline No $(\%)$ of primigravidas & $19(39)$ & $56(33)$ \\
\hline No $(\%)$ of multigravidas & $30(61)$ & $115(67)$ \\
\hline \multicolumn{3}{|l|}{ No (\%) with family history of: } \\
\hline Thyroid disease & $12(25)$ & $26(15)$ \\
\hline Diabetes mellitus & $15(31)$ & $36(21)$ \\
\hline Pernicious anaemia & $1(2)$ & $5(3)$ \\
\hline \multirow{2}{*}{\multicolumn{3}{|c|}{ No (\%) with family history of thyroid disease and thyroid }} \\
\hline & & $5(3)^{\star}$ \\
\hline No for whom information on feeding available & & 157 \\
\hline \multirow{2}{*}{\multicolumn{3}{|c|}{ No (\%) breast feeding (weeks): }} \\
\hline & & \\
\hline$<2$ & $4(9)$ & $14(9)$ \\
\hline $2-6$ & $9(19)$ & $24(15)$ \\
\hline$>6$ & $10(22)$ & $31(20)$ \\
\hline Mean (2 SD) birth weight of neonate ( $g$ ) & $3390(560)$ & $3420(500)$ \\
\hline Sex of neonate (female:male) & $0.75: 1$ & $1 \cdot 28: 1$ \\
\hline Mean (2 SD) size of thyroid gland at booking $(\mathrm{cm})$ & $2 \cdot 0(1 \cdot 7)$ & $1.98(1.6)$ \\
\hline No for whom information on smoking available & 46 & 167 \\
\hline \multicolumn{3}{|l|}{ No (\%) smoking (cigarettes daily): } \\
\hline$>20$ & $7(15)$ & $7(4) \dagger$ \\
\hline $10-20$ & $15(33)$ & $42(25)$ \\
\hline$<10$ & & $13(8)$ \\
\hline 0 & $24(52)$ & $105(63)$ \\
\hline
\end{tabular}

$\star$ Predictive value for development of postpartum thyroid dysfunction is $11 / 16=69 \%$. $\mathrm{tx}^{2}=11 \cdot 68, \mathrm{df}=3, \mathrm{p}<0 \cdot 01$. 
booking between the two groups. Although the number of non-smokers was similar in the two groups, there was a significant difference $(p<0.01)$ in the daily cigarette consumption post partum, which was mainly attributable to the higher proportion of heavy smokers ( $>20$ cigarettes a day) in the women developing postpartum thyroid dysfunction.

\section{Discussion}

A normal reference range for thyroid function within pregnancy and for the 12 months post partum was established from 120 women, and on this basis $49(22 \%)$ women were defined as having postpartum thyroid dysfunction; these women had no history of autoimmune thyroid disease. The estimated prevalence in the unselected population examined $(n=901)$ was thus $16 \cdot 7 \%$, which may seem high compared with that of $5 \cdot 5-8 \cdot 5 \%$ reported from other studies. ${ }^{8911}$ This difference, however, between this and previous studies probably reflects several variables, including early postpartum examination, more frequent and longer duration of follow up post partum, and varying definitions of postpartum thyroid dysfunction. Most importantly, in attempting to determine the factors associated with the development of thyroid dysfunction we placed particular emphasis on the presence or absence of microsomal antibody activity at booking to characterise the groups of women selected for the study; this is bound to have influenced the prevalence obtained. A true indication of the prevalence could be obtained only by following up a much larger unselected population throughout pregnancy.

The presentation and onset of the various forms of postpartum thyroid dysfunction were variable and usually transient. Most women who developed changes in thyroid function did so in the first six months post partum. The transient hyperthyroid phase usually occurred from one to four months post partum and lasted for one to three months. In contrast, transient hypothyroidism usually occurred from four to eight months post partum and lasted for one to four months. When the transient hyperthyroid phase was followed by transient hypothyroidism the hypothyroidism tended to occur sooner than when hypothyroidism occurred alone. In general, most cases of postpartum thyroid dysfunction were silent without any clinical symptoms. This may be because most women attributed their symptoms, if any, to expected postpartum fatigue, and hence clinical diagnosis was difficult. Clinical manifestations were commoner in those who developed transient hyperthyroidism followed by transient hypothyroidism and were related to the severity of the biochemical dysfunction. The low rates of uptake of radioactive iodine and absence of antibodies to thyroid stimulating hormone receptors in relation to the episodes of transient hyperthyroidism exclude the possibility of Graves' disease as the cause of the hyperthyroidism.

The development of thyroid dysfunction was not related to age, parity, frequency and duration of breast feeding, a family history of autoimmune disease (including thyroid disease), sex and birth weight of neonates, or the size of the thyroid gland at booking, but it was related to smoking more than 20 cigarettes a day. Several constituents of tobacco smoke have antithyroid activity-for example, thiocyanate, which is the metabolite of hydrogen cyanide, has a molecular size similar to that of iodide. In addition, both inhibition of thyroid hormone production ${ }^{17}$ and increased serum thyroid hormone concentrations ${ }^{18}{ }^{19}$ have been described in smokers. The mechanism by which cigarette smoking may predispose to the development of postpartum thyroid dysfunction remains to be established.
Autoantibodies to thyroglobulin were present in only a few women who developed postpartum thyroid dysfunction. In contrast, most women with the dysfunction had detectable thyroid microsomal autoantibodies during the study. Despite the high prevalence of microsomal autoantibodies at booking (55\%) and post partum $(65 \%)$, these antibodies were of limited predictive value for the development of postpartum thyroid dysfunction. Microsomal autoantibodies and a family history of thyroid disease occurred in $70 \%$ of women with postpartum thyroid dysfunction. Although the clinical history and presentation of thyroid dysfunction post partum are being increasingly well defined, much information is still required to recognise its contribution to maternal morbidity. If transient changes in thyroid function are shown to be associated with maternal ill health post partum ${ }^{20}$ then screening programmes for women at risk will be worth while. The high prevalence of changes in mood, behaviour, and ability to cope in women post partum means that a possible association with altered thyroid function is important and needs to be addressed urgently.

We thank Glenys Roberts and Theresa Chakrovarty for collecting. postpartum blood samples and Linda John for help in assaying the serum samples. We thank Dr Robert Newcombe and his colleagues in the department of medical statistics, University of Wales College of Medicine, for their help in preparing the data for analysis and advice on the methods of analysis. We acknowledge the support of the Welsh Office, Amersham International PLC, the Mid Glamorgan Area Health Authority, and the Camilla Samuel Fund. We thank Miss Alison Dix for her expert secretarial help.

\section{References}

1 Amino N, Miyai K. Autoimmune endocrine disease. New York: Wiley and Sons, 1983. Davies TF, Cobin R, Thyroid disease in pregnancy and the post-partum period. Mt Sinai $\mathcal{F}$ Me (NY) 1985;52:59-77

3 Jansson R, Karlsson A. Autoimmune thyroid disease in pregnancy and the post-partum period. In: McGregor AM, ed. Immunology of endocrine diseases. Lancaster: MTP Press Ltd, 1986: 181-96.

4 Gardiner-Hill H. Pregnancy complicating simple goitre and Graves' disease. Lancet 1929;i:120-4. 5 Robertson HEW. Mild hypothyroidism in Christchurch. NZ Med f 1946;45:170-6.

6 Cooke RT. Endocrine factors in affective disorders. Lancet 1953;ii:298-9.

7 Ginsberg J, Walfish PG. Post-partum transient thyrotoxicosis with painless thyroiditis. Lancet 1977;i:1125-8.

8 Amino $\mathrm{N}$, Mori $\mathrm{H}$, Iwatani $\mathrm{Y}$, et al. High prevalence of transient post-partum thyrotoxicosis and hypothyroidism. N Engl f Med 1982;306:849-52.

9 Jansson R, Bernander S, Karlsson A, Levin K, Nilsson G. Autoimmune thyroid dysfunction in the post-partum period. $f$ Clin Endocrinol Metab 1984;58:681-7.

10 Goldman JM. Postpartum thyroid dysfunction. Arch Intern Med 1986;146:1296-9.

11 Turney S, Nikolai T, Roberts R. The prevalence and clinical course of post-partum lymphocytic thyroiditis. In: Proceedings of 64th annual meeting of the American Endocrine Society, San Francisco, 1982. Bethesda: American Endocrine Society, 1982:219. (Abstract 557.)

$12 \mathrm{McG}$ regor AM, Hall R, Richards C. Autoimmune thyroid disease and pregnancy. Br Med $\mathcal{f}$ $1984 ; 288: 1780-1$.

13 Weetman AP, Rennie DR, Hassman R, Hall R, McGregor AM. Enzyme-linked immunoassay of monoclonal and serum microsomal autoantibodies. Clin Chim Acta 1983;138:237-44.

14 Rapoport B, Pillarisetty RJ, Herman EA, Clark OH, Congco EG. Production of a nonimmunoglobulin thyroid stimulator by human lymphocytes during mixed culture with human immunoglobulin thyroid stimulator by hum

15 Rapoport B, Greenspan FS, Filetti S, Pepitone M. Clinical experience with a human thyroid cell bioassay for thyroid stimulating immunoglobulin. F Clin Endocrinol Metab 1984;58:332-8.

16 Weetman AP, Ratanachaiyavong S, Middleton GW, et al. Prediction of outcome in Graves' diseas after carbimazole treatment. Qf Med 1986;59:409-19.

17 Sepkovic DW, Haley NJ, Wynder EL. Thyroid activity in cigarette smokers. Arch Intern Med 1984;144:501-3.

18 Melander A, Nordenskjold E, Lundh B, Thorell J. Influence of smoking on thyroid activity. Acta Med Scand 1981;209:41-3.

19 Christensen SB, Ericsson UB, Janzon L, Tibblin S, Melander A. Influence of cigarette smoking on goitre formation, thyroglobulin and thyroid hormone levels in women. $f$ Clin Endocrinol on goitre formation,

20 Anonymous. Postpartum thyroiditis [Editorial]. Lancet 1987;i:962.

(Accepted 20 October 1987) 